\title{
Process intensification in Desalination operation in mesoscale systems
}

\author{
Abir Chakravorty*1 \\ ${ }^{1}$ Ph.D., Indian Institute of Technology Kharagpur, India
}

\begin{abstract}
Development of desalination technologies has been identified as vital to fulfilling future water demand. Directional solvent extraction is one of the promising membrane-less seawater desalination method. Membrane based desalination technologies incur a higher cost and are subjected to fouling after certain period of time of operation and needs regular maintenance and monitoring. It is believed that, overcoming these drawbacks is possible by working in the millimeter scale through the incorporation of pulsatile flow and air damper. This work presents a theoretical approach designed for a certain nominal length of an air damper, placed on the top of the extraction column, with the flow in the desalination unit being semi pulsatile combined with secondary pulsation generated due to air suspension during solvent extraction applied for desalination operation. Henceforth a theoretical approach based on the above stated parameters, it is found theoretically that with increase in flow pulsation amplitude and frequency the extracted salt concentration in solvent increases. The application of infra red radiation in preheating section with the help of a infrared heating device is the crucial part of DSE process, cooling is planned to achieve via a heat exchanger or atmospheric cooling. The total exergy and energy calculations will be conducted to see the energy requirement for the process. It is planned to calculate the salt separation efficiency of sea water (on the basis of WHO guidelines) to fresh water, alongwith flow rate and processing time.
\end{abstract}

*Email: abir.cty2015@gmail.com; abir.chakravorty@yahoo.com; OrCID ID: https://orcid.org/00000002-9253-2594 


\section{Introduction}

Directional solvent extraction (DSE) is an emerging membrane-free liquid-liquid extraction process to desalinate water using low-grade heat $[1,2,3,4]$. Several unique features make DSE a potentially desalination technology: a) it is thermally driven and utilizes low-grade heat; b) it does not require the use of membranes; c) there are opportunities to intensify, modularize and customize the process; d) there is a vast solvent molecular design space $[5,6]$. Solvent extraction for desalination were explored by Hood and Davison in the 1960s [7, 8] who used amines as solvents and by Johnson in the 1970s [9] who proposed mixtures of alcohols and nitriles as primary solvents. Later these solvents were found undesirable due to the significant residual presence in the recovered water [10]. Lazare established a pilot plan using a technology combining liquid-liquid extraction and membranes $[11,12]$. This process, however, still rely on the use of membranes whch are prone to fouling and needs maintenance on regular basis. Directional solvent extraction desalination (DSE) was first presented by Davison and associates in 1960s as an alternative desalination method, where water is broken down in a dissolvable at high temperature and recouped by tapping it at low temperature [13]. Hypothetically, there are scarcely any natural solvents with high extremity what's more, insolubility in water that are equipped for dissolving the water while disposing of other impurities. [14, 15]. Sanap et al. found that the contactor, used to extract water into the dissolvable was under extreme pressures and allowed just three phases of fluid contact, which prompted more prominent vitality needs [16].

Recent desalination innovations can be separated into two sections: (1) vanishing based cycles, for example, multi-stageflash (MSF) furthermore, Multi Effect Distillation (MED); and (2) film based cycles like Reverse Osmosis (RO) [17], but the same require excess energy to dissipate saline water, and membrane separations require the utilization of high-grade power and membranes. Also, these desalination measures either depend on generally high temperature warm energy, which is normally received from consuming non-renewable energy sources. MSF refining requires energy utilization of around 50 to $80 \mathrm{kWh} / \mathrm{m}^{3}$ also, electrical energy utilization of 2.5 to $5 \mathrm{kWh} / \mathrm{m}^{3}$ [18]. While, MED devours less warm energy somewhere in the range of 40 and $60 \mathrm{kWh} / \mathrm{m}^{3}$ also, electrical energy utilization around $2.5 \mathrm{kWh} / \mathrm{m}^{3}$ [19]. RO (Reverse Osmosis), then again, requires 
electrical energy utilization around 3.7 to $8 \mathrm{kWh} / \mathrm{m}^{3}$ [20]. The dependence on petroleum product, which isn't sustainable, additionally causes ecological issues, for example, ozone depleting substance discharge. Exploring new water desalination measures that are more energy efficient, utilize sustainable power source or potentially cost less is an essential objective to accomplish maintainable advancements.

The potential of utilizing low-grade, low temperature heat sources and membranefree operation, solvent extraction based desalination which was first researched by Davidson et al. in 1960 [7]. They used amines as a directional solvents to extract pure water from saline water. Since amine solvents are highly soluble in water, which leads to contamination in the recovered water. To address the issue of the Davidson's study, new extraction solvents, such as soyabean oil, hexanoic acid, octanoic and decanoic acid, were proposed and investigated by Chen and coworkers $[21,22,14]$. In their studies, the properties of a directional solvent are elaborated as: 1) water is soluble in solvent; 2) the solubility of water in solvent increases with temperature; 3) the solvent is insoluble in water; and 4) the salt do not dissolve in solvent. Such features will allow extracting fresh water from saline sources while leaving no or little residue, including solvent and salts, in the recovered water. Bajpayee's study was focused on laboratory experiments to obtain product water yield, recovery water salinity, and recovery ratio for several directional solvents [21]. The study also predicted thermal energy consumption for a continuous process using a simple process modeling. Using octanoic acid, it was found that the energy consumptions for the process without heat recovery was $1250 \mathrm{kWh} / \mathrm{m}^{3}$. Assuming $80 \%$ heat recovery, the thermal energy consumption was expected to be reduced to 250 $k W h / m^{3}[21]$.

Modern desalination technologies, including evaporative and reverse osmosis systems, are energy-intensive and not suitable to treat high salinity water. Evaporative systems such as multi-stage flash (MSF) and multi-effect distillation (MED) utilize thermal energy in the range of $90^{\circ} \mathrm{C}$ and $55^{\circ} \mathrm{C}$ respectively in the range to evaporate and condensate water respectively in the range to evaporate and condensate water [23]. These systems require resistant and costly materials [24] and are heat intensive (26.29-83.06 $\left.k W h / m^{3}\right)$. In contrast, membrane-based technologies such as reverse osmosis (RO) use 
mechanical work to overcome the osmotic pressure across a membrane. Membrane-based technologies use significant electricity inputs, need frequent membrane replacement, and have limited effectiveness when treating concentrated brines [6]. New technologies, including electrodialysis and forward osmosis, show promise to reduce energy consumption and lower costs. For example, osmotically assisted reverse osmosis (OARO) and mechanical vapor compression (MVC) are suitable to treat high salinity brines $(140,000$ ppm and 150,000 ppm respectively) [15]. Nevertheless, MVC energy consumption is high (single-effect MVC 23-42 $\mathrm{kWh} / \mathrm{m}^{3}$, double-effect MVC $20 \mathrm{kWh} / \mathrm{m}^{3}$ ). OARO, RO, and other membrane-based technologies are often susceptible to membrane fouling at high salt concentrations [25]. While hybrid desalination systems paired with renewable energy sources are well-studied [26, ?], there is limited work of technologies suitable for high salinity brines.

Directional solvent extraction can overcome limitations of thermal and membranebased systems by efficiently separating high salinity feeds with low grade waste heat in the range of $40^{\circ}-80^{\circ} \mathrm{C}$ exploits thermoresponsive solvents that extract water from salty mixtures at elevated temperatures and the releases the water when cooled. Directional solvent has several features (a) water dissolves in the solvent at an elevated temperature, (b) the solvent is virtually insoluble in water, (c) the solvent does not dissolve salts. The features of DSE are several and distinct and the solvent can be reutilized. (i) DSE process is a membrane free operation, (ii) DSE operates in liquid state which reduces the size and complexity of the equipment, (iii) DSE can be paired with state-of-art and economic heat sources such as infra red assisted heater [27, 2, 28, 29]

\section{Methodology}

A lab scale continuous DSE process is planned on a pulsatile flow extractors processes which are till now well established for less retention time [30], enhanced mixing [31], high heat and mass transfer [32], low process time. It is planned to conduct the experimentation in meso scale systems i.e. millimeter size channels which are well established to retain the advantage of high surface to volume ratio [33], but also avoiding the complexities faced in designing and operating in micro reactor. In the meso scale systems both gravitational and surface forces are equally important. It is planned to experiment on 
different pulsation parameters combined with air dampers, without using any kind of extra machinery for mechanical stirring as the pulsation will inherently be present in the flow $[33,34]$. It is planned to evaluate improvement in separation efficiency of salt and other heavy metal pollutants from water with different kinds of solvent such as soyabean oil, decanoic acid, octanoic acid, and others. It is planned to utilize state-of-art as well as economic heat source such as infrared radiation [35]. Different solvents and saline water will be fed into different ' $\mathrm{T}$ ' shaped [kashid, koushik] mesoscale systems fitted with air dampers. The pulsations will be incorporated via dosing or peristaltic pumps. The application of infra red radiation in preheating section and the meso scale reactor shall reside in an enclosure consisting of infrared heating device of $100 \mathrm{~W}$ and $220 \mathrm{~V}$, [27] the process will increase the working temperature for the DSE process, cooling is planned to achieve via a heat exchanger or a chiller or, atmospheric cooling. The total exergy and energy calculations will be conducted to see the energy requirement for the process $[23,2]$. Water inlet salinity will be kept around e.g. $35000 \mathrm{ppm} \mathrm{NaCl}$. It is planned to calculate the salt separation efficiency purity of water (on the basis of WHO guidelines) with salt water to fresh water processing time.

Statistical model equations are planned to be developed using response surface methodology. The optimal conditions for IR temperature, flow rate, pulsation parameters, volume of air damper, channel width and length will be investigated. Finally molecular simulations using Gromacs/ PACKMOL will be used to model bonded and non bonded interactions of solvent molecules under the influence of pulsatile flow with air damper [6, 36].

\section{$3 \quad$ Preliminary theoretical modelling}

In this section, it is attempted to extend a theoretical model from [37] and use the same as a basis to develop a relation which will evaluate the transfer of water from the sea-water to the solvent. Assuming the entire extraction operation is carried out at an uniform temperature. The concentration of water in the solvent extracted $C_{w, \text { So out }}$ at the outlet of the desalination unit. Further the separation of pure water from the directional solvent 
is achieved by cooling, at the end of the extraction process. Performing a mass balance on all four branches of the test section having an air damper,

$$
\rho_{S o} A_{p}(2 a f)+\rho_{S W} u_{S W} A_{t}=A_{t} \rho_{m} \frac{d l}{d t}-A_{t} \rho_{a i r} \frac{d x}{d t}
$$

where the subscript 'So' stand for solvent, subscript 'p' stands for piston, 'Sw' stands for salt water, 't' for tube, 'm' stands for mixture, 'l' stands for the differential length, 'dt' stands for the differential time, 'dx' stands for the differential change in length of liquid level within the air damper. Presuming the oscillations because of the air column to be following damped straightforward periodic motion, ' $\mathrm{x}$ ' for the liquid level within the air damper is written as, The liquid level within the air damper is written as

$$
x=a e^{\left(-b t / 2 m_{l}\right)} \cos \left(\omega_{o} t+\phi\right)
$$

Accepting the phase contrast between two pumping units be zero,

$$
x=a e^{\left(-b t / 2 m_{l}\right)} \cos \left(\omega_{o} t\right)
$$

where b refers to the damping constant [38],

$$
\omega_{0}=\sqrt{\frac{k}{m_{l}}-\frac{b^{2}}{4 m_{l}^{2}}} ; \text { wherem } m_{l}=\rho_{m} A_{t} l_{t}
$$

Also, the linear stiffness 'k' can be represented as,

$$
k=\frac{p_{0} E A_{t} L_{0}}{\left(L_{0}-x\right)^{(E+1)}}
$$

E (the adiabatic constant of the gas) the value selected of which is 1.4 for air. Assuming small deflections of the liquid in the damper ' $k$ ' is approximated as [39]. Replacing the value of $\omega_{0}$ in $(3)$ we get,

$$
x=a e^{\left(-b t / 2 m_{l}\right)} \cos \left[\left(\sqrt{\frac{p_{0} E A_{t}}{m_{l} L_{0}^{E}}-\frac{b^{2}}{4 m_{l}^{2}}}\right) t\right]
$$

Differentiating w.r.t. $\mathrm{x}$ we get,

$$
\begin{aligned}
& \frac{d x}{d t}=-\frac{a b}{2 m_{l}} e^{-\left(b t / 2 m_{l}\right)} \cos \left[\left(\sqrt{\frac{p_{0} E A_{t}}{m_{l} L_{0}^{E}}-\frac{b^{2}}{4 m_{l}^{2}}}\right) t\right]-a e^{-\left(b t / 2 m_{l}\right)} . \\
& \sqrt{\frac{p_{0} E A_{t}}{m_{l} L_{0}^{E}}-\frac{b^{2}}{4 m_{l}^{2}}} \sin \left[\left(\sqrt{\frac{p_{0} E A_{t}}{m_{l} L_{0}^{E}}-\frac{b^{2}}{4 m_{l}^{2}}}\right) t\right]
\end{aligned}
$$


Replacing the value of $\frac{d x}{d t}$ from equation (7) in equation (1),

$$
\begin{aligned}
& A_{t} \rho_{m} \frac{d l}{d t}=\rho_{S o} A_{p}(2 a f)+\rho_{S w} u_{S w} A_{t}+ \\
& \mathrm{A}_{t} \rho_{a i r}\left[\begin{array}{l}
-\frac{a b}{2 m_{l}} e^{-\left(b t / 2 m_{l}\right)} \cos \left[\left(\sqrt{\frac{p_{0} E A_{t}}{m_{l} L_{0}^{E}}}-\frac{b^{2}}{4 m_{l}^{2}}\right) t\right] \\
-a e^{-(b t / 2 m)} \cdot \sqrt{\frac{p_{0} E A_{t}}{m_{l} L_{0}^{E}}-\frac{b^{2}}{4 m_{l}^{2}}} \sin \left\{\left(\sqrt{\frac{p_{0} E A_{t}}{m_{l} L_{0}^{E}}-\frac{b^{2}}{4 m_{l}^{2}}}\right) t\right\}
\end{array}\right]
\end{aligned}
$$

After dividing the both sides of the equation by $A_{t} \rho_{m}$,

$$
\begin{aligned}
& \frac{d l}{d t}=\frac{A_{p} \rho_{S o}}{A_{t} \rho_{m}}(2 a f)+\frac{u_{S w} \rho_{S w}}{\rho_{m}}+ \\
& \frac{\rho_{a i r}}{\rho_{m}}\left[\begin{array}{l}
-\frac{a b}{2 m_{l}} e^{-\left(b t / 2 m_{l}\right)} \cos \left[\left(\sqrt{\frac{p_{0} E A_{t}}{m_{l} L_{0}^{E}}-\frac{b^{2}}{4 m_{l}^{2}}}\right) t\right] \\
-a e^{-(b t / 2 m)} \cdot \sqrt{\frac{p_{0} E A_{t}}{m_{l} L_{0}^{E}}-\frac{b^{2}}{4 m_{l}^{2}}} \sin \left\{\left(\sqrt{\frac{p_{0} E A_{t}}{m_{l} L_{0}^{E}}-\frac{b^{2}}{4 m_{l}^{2}}}\right) t\right\}
\end{array}\right]
\end{aligned}
$$

Implementing a material balance for water which is migrating from saline solution to directional solvent

$$
d N_{W}=-\left.Q_{S o} C_{W, S o}\right|_{l}+\left.Q_{S o}^{\prime} C_{W, S o}\right|_{l+d l}=k_{z} a\left(C^{*}{ }_{W, S o}-C_{W, S o}\right) A_{t} d z(10)
$$

where $C_{W, S o}$, concentration of water in solvent, $Q_{S o}$ and $Q_{S o}^{\prime}$ are the solvent flow rates at the inlet and exit respectively. Assuming the solvent flow rates to be equal at the inlet and exit we get,

$$
\begin{aligned}
& Q_{W, S o}\left(d C_{W, S o}\right)=k_{L} a_{\text {int }}\left(C_{W, S o}^{*}-C_{W, S o}\right) A_{t} \cdot d l \\
& \frac{d C_{W, S o}}{C_{W, S o}^{*}-C_{W . S o}}=\frac{k_{L} a_{\mathrm{int}} A_{t}}{Q_{W, S o}} \times \\
& {\left[\begin{array}{l}
\frac{A_{p} \rho_{t}}{A_{t} \rho_{m}}(2 a f)+\frac{u_{W} \rho_{W}}{\rho_{m}}+ \\
\frac{\rho_{a i r}}{\rho_{m}}\left[\begin{array}{l}
-\frac{a b}{2 m_{l}} e^{-\left(b t / 2 m_{l}\right)} \cos \left[\left(\sqrt{\frac{p_{0} E A_{t}}{m_{l} L_{0}^{E}}-\frac{b^{2}}{4 m_{l}^{2}}}\right) t\right] \\
-a e^{-(b t / 2 m)} \cdot \sqrt{\frac{p_{0} E A_{t}}{m_{l} L_{0}^{E}}-\frac{b^{2}}{4 m_{l}^{2}}} \sin \left\{\left(\sqrt{\frac{p_{0} E A_{t}}{m_{l} L_{0}^{E}}-\frac{b^{2}}{4 m_{l}^{2}}}\right) t\right\}
\end{array}\right]
\end{array}\right]}
\end{aligned}
$$

Implementing solute balance between inlet and at a distance 1 from the inlet on the solvent phase

$$
\begin{gathered}
Q_{S o} C_{W, S o, i n}+Q_{S W} C_{W, S W, i n}=Q_{S o}^{\prime} C_{W, S o}+Q_{S W}^{\prime} C_{W, S W}(13) \\
C_{W, S W}=\frac{Q_{S o} C_{W, S o, i n}+Q_{S W} C_{W, S W, i n}-Q_{S o}^{\prime} C_{W, S o}}{Q_{S W}^{\prime}(14)}
\end{gathered}
$$


Assuming $Q_{S W}$ and $Q_{S W}^{\prime}$, also $Q_{S o}$ and $Q_{S o}^{\prime}$ to be equal we get,

$$
C_{W, S W}=\frac{Q_{S o}}{Q_{S W}}\left(C_{W, S o, i n}-C_{W, S o}\right)+C_{W, S W, \text { in }}
$$

The concentration of water in the solvent is in equilibrium with the water in the saline water solution, Therefore,

$$
C_{W, S o}=m C_{W, S W}
$$

or,

$$
C_{W, S o}=m \frac{Q_{S o}}{Q_{S W}}\left(C_{W, S o, \text { in }}-C_{W, S o}\right)+m C_{W, S W, \text { in }}
$$

On integrating we get,

$$
\begin{aligned}
& \frac{-1}{\left(1+m \frac{Q_{S o}}{Q_{S w}}\right)} \ln \left[\frac{C_{W, \text { So,out }}\left(1+m \frac{Q_{S o}}{Q_{S w}}\right)-m\left(C_{W, S W, \text { in }}+\frac{Q_{S o}}{Q_{S w}} C_{w, i n}\right)}{C_{W, S W, \text { in }}\left(1+m \frac{Q_{S o}}{Q_{S w}}\right)-m\left(C_{W, S W, \text { in }}+\frac{Q_{S o}}{Q_{S w}} C_{w, i n}\right)}\right]=
\end{aligned}
$$

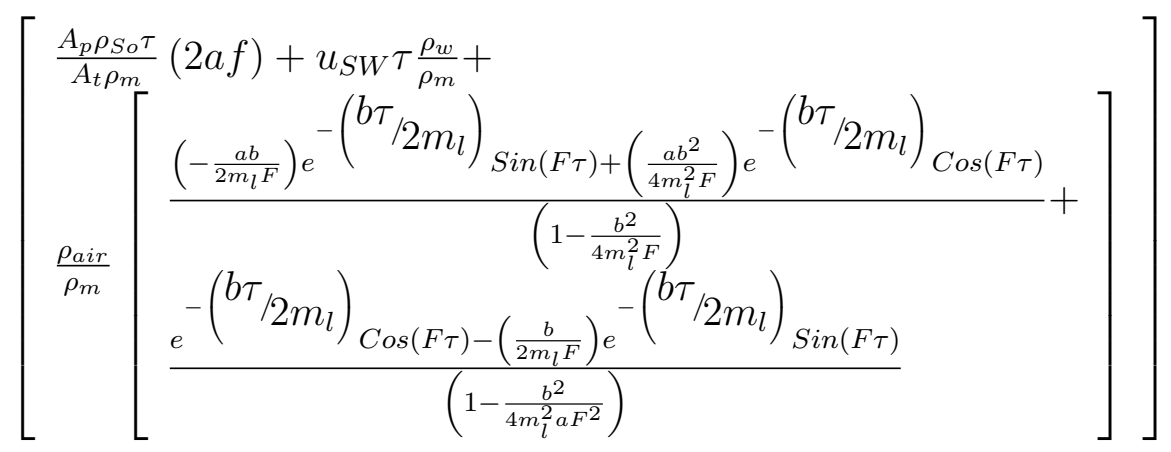

where, $F=\left(\sqrt{\frac{p_{0} E A_{t}}{m_{l} L_{0} E}-\frac{b^{2}}{4 m_{l}^{2}}}\right)$ where $L_{0}$ is the complete length of the air suspension, Putting the value of in equation 18 and rearranging we get,

Putting the value of $C_{W, S o, i n}=0$ in equation 18 and rearranging we get,

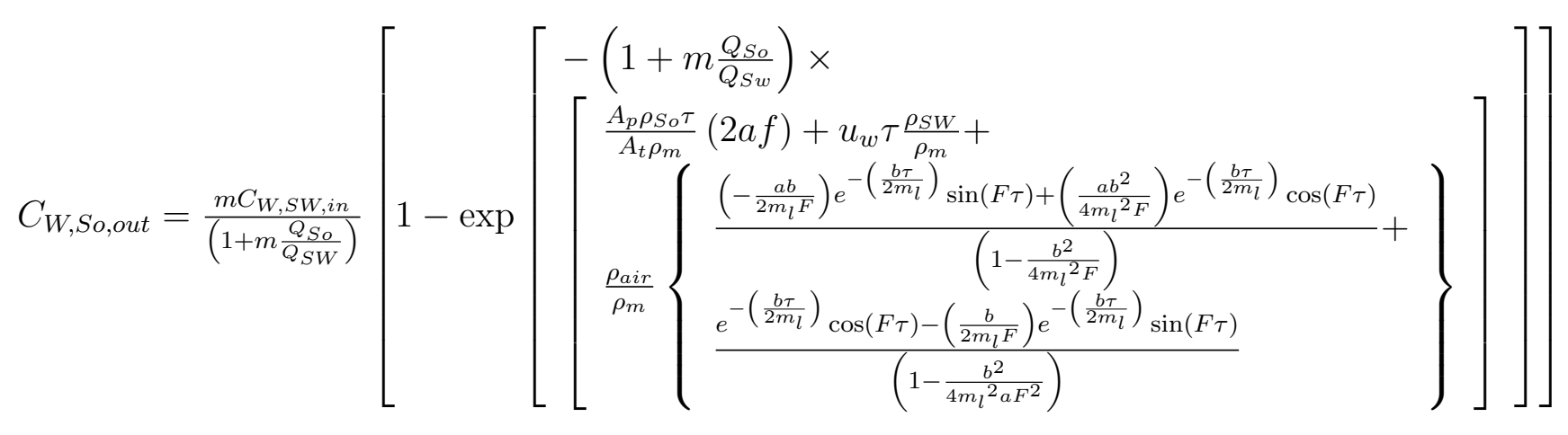

$C_{W, \text { So,out }}$ gives the final concentration of water which got extracted in the directional solvent. 


\section{Preliminary Results and Discussion}

The section starts with the interpretation for the theoretical results of the extracted concentration of water from the salt-water to the solvent. The $C_{w, S o, \text { out }}$ is an indication of the extracted concentration of water which varies with flow frequency and amplitude. Then it is followed by a comparison of the theoretical results with experimental values obtained for a similiar kind of two-phase three component system [37].

The section concludes, discussing performance measured on the basis of species transfer and volume consumed of the desalination units for three different lengths of the desalination unit . It is revealed that the larger length of the extraction column may not correspond to the highest salt extraction rate per unit power consumption in a case where there is air filled elastic column attached at the top arm of the experimental section, in this case small to the moderate length of the reactor with air-filled column at the top can deliver the same performance. Further experiments and optimization of the air column are planned in the near future.

It is observed from the graphs of figure 1 that with increase in frequency and amplitude of pulsation the extracted water concentration in solvent increases and this trend is followed for varying desaltation unit lengths viz. figures 2,3. From the plot it can be interpreted that increasing flow amplitude, a, and frequency, results in higher flow rate which in turn results in rise in shear rate leading to increased concentration of salt extracted in the solvent [37], [40].

The figure 2 represents the variation of extracted concentration of water in solvent extracted from saltwater with amplitude and frequency for $80 \mathrm{~cm}$ length of desalination unit having $19 \mathrm{~cm}$ of air damper attached. It has been earlierly established that larger the amplitude and frequency of the pump are, larger the magnitude of shear is in the central limb of the cross-junction and larger is the amount extracted. This is the reason why the plot has a net linear trend with a positive slope as was obtained through equation 19 of the mathematical formulation.

The plot in figure 3 represents the extracted concentration of water in directional 


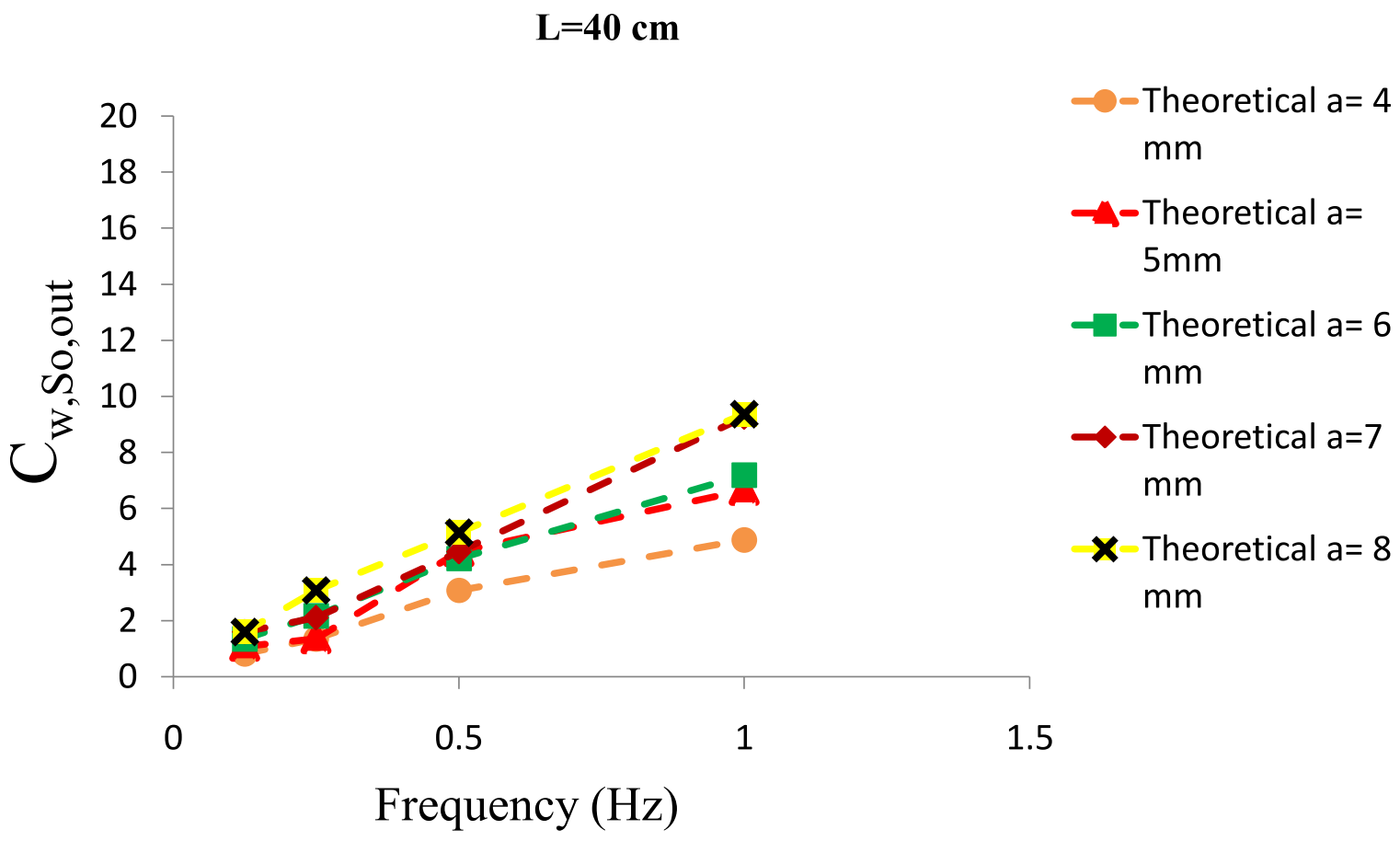

Figure 1: Variation of extracted concentration of water in solvent extracted from saltwater with amplitude and frequency for $40 \mathrm{~cm}$ length of desalination unit having $19 \mathrm{~cm}$ of air damper attached at the top of the unit 


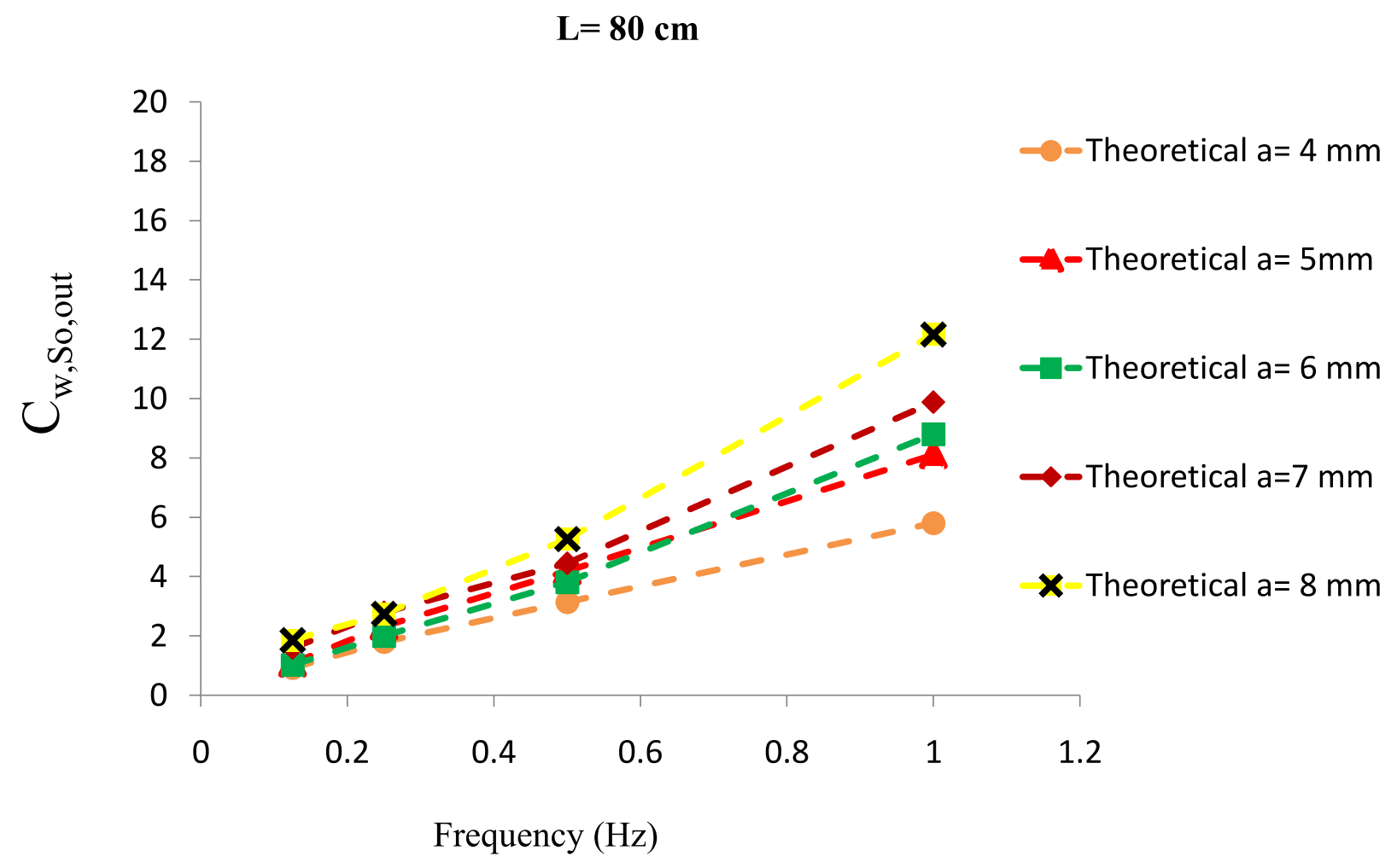

Figure 2: Variation of extracted concentration of water in the solvent extracted from saltwater with amplitude and frequency for $80 \mathrm{~cm}$ length of desalination unit having $19 \mathrm{~cm}$ of air damper attached at the top of the unit 


\section{$L=142 \mathrm{~cm}$}

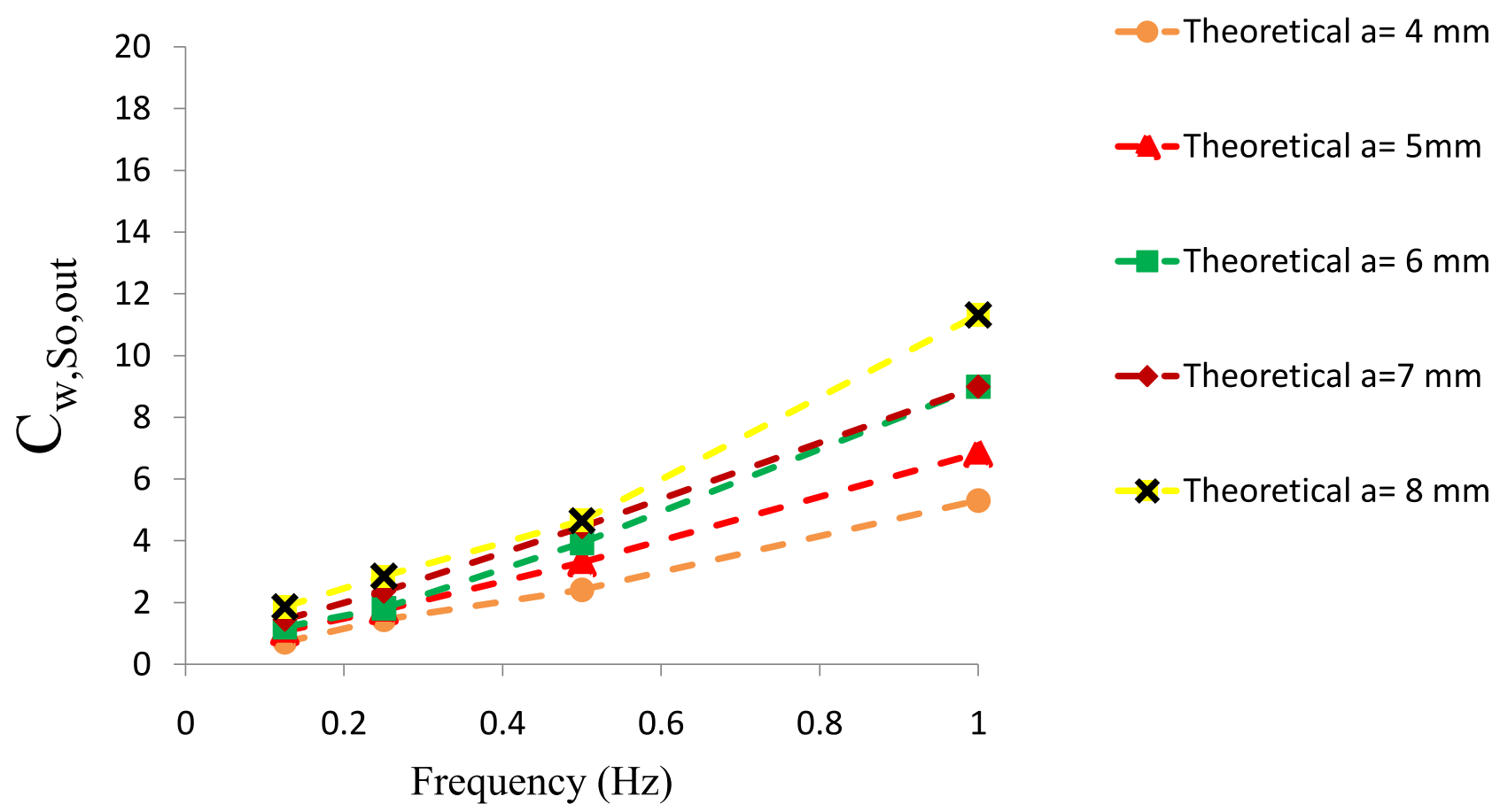

Figure 3: Variation of extracted concentration of water in the directional solvent extracted from saltwater with amplitude and frequency for $142 \mathrm{~cm}$ length of desalination unit having $19 \mathrm{~cm}$ of air damper attached at the top of the unit

solvent with amplitude and frequency for $142 \mathrm{~cm}$ length of desalination unit having 19 $\mathrm{cm}$ of air damper attached at the top of the unit. It is observed from the figures $3,2,1$ that with increase in frequency and amplitude, the extracted concentration of salt, also the smaller and moderate lengths of the extraction column (i.e. $40 \mathrm{~cm}, 80 \mathrm{~cm}$ ) deliver comparable species transfer/extraction as of the longer length of the column, resulting in saving of reactor space and volume (Process intensification).

Likewise, it is clear from the above expressed figures that with the incorporation of the same length of air column with identical volume of air at the top appendage of crossintersection the extraction section having $40 \mathrm{~cm}$ delivers, a similar extraction concerning the segment of $142 \mathrm{~cm}$ length. The explanation can be found as a higher auxiliary pulsations created in $40 \mathrm{~cm}$ length of the extraction segment, contrasted with 80 , and $142 \mathrm{~cm}$, all having a similar length of air segment with identical volume of air at the highest point of cross-intersection. From equation 4 the denominator term $m_{l}$ is getting 


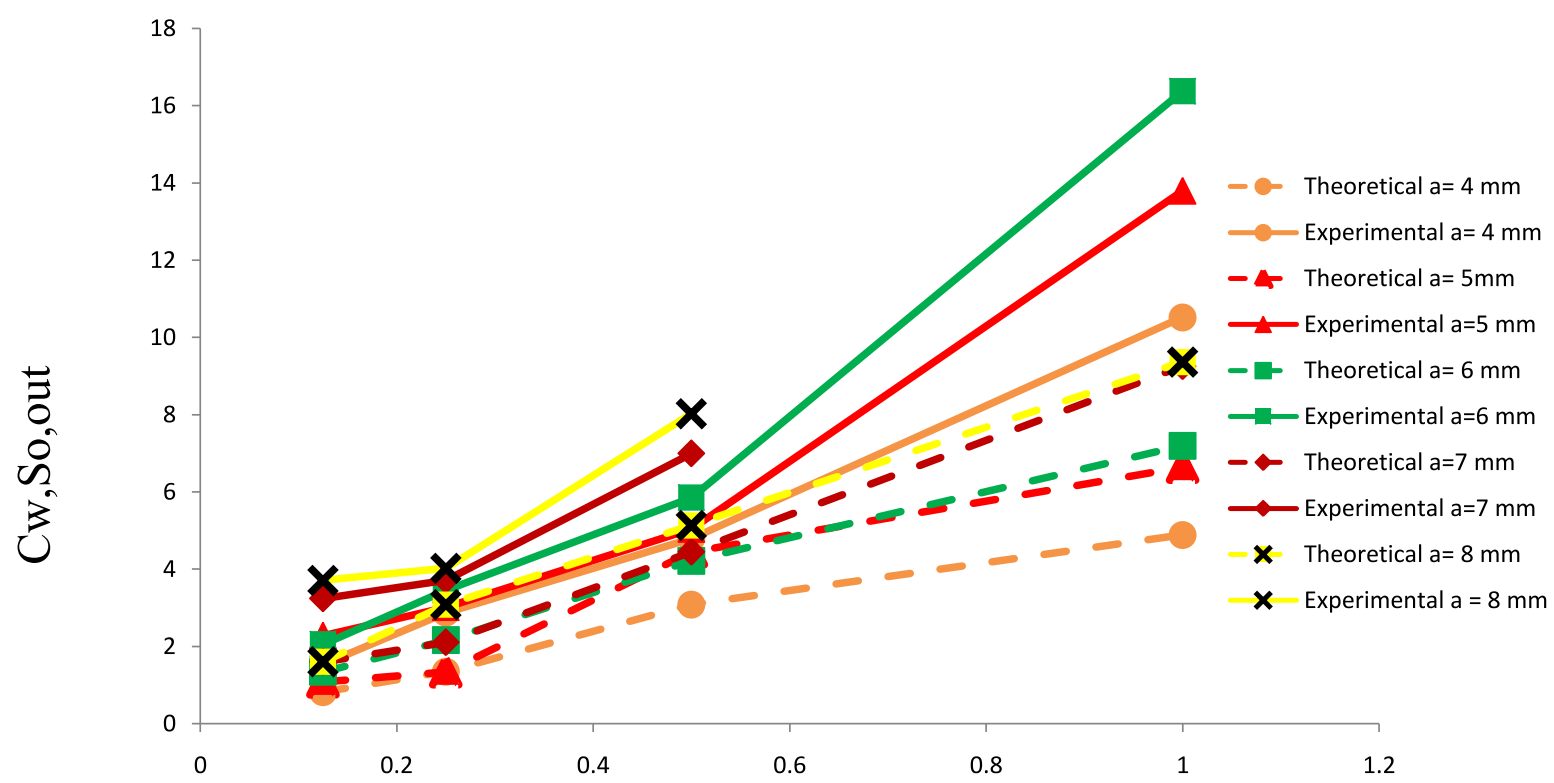

Frequency $(\mathrm{Hz})$

Figure 4: Theoretical validation of extracted water in solvent extracted from saltwater with amplitude and frequency for $40 \mathrm{~cm}$ length of desalination unit having $19 \mathrm{~cm}$ of air damper attached at the top of the unit

diminished for the segment length of $40 \mathrm{~cm}$ of the desalination unit when contrasted with 80 and $142 \mathrm{~cm}$ resulting in enhanced angular frequency.

Figures 4, 5, and 6 represents the above explained plots in figure 1, 2, and 3, but with validation of the theory with experimental results of the research manuscript [37]. The increase in parameter 'af' increases the Oscillatory Reynolds number concomitantly increasing the Womersley number, thereby indicating the effect of viscous forces becoming less dominant in comparison to inertial forces. Leading to the increased shearing action of the phases.

The application of pulsation leads to an increased maximum flow rate compared to the average condition, thereby momentarily increasing the shear which is higher than the average condition without affecting the residence time parameter. Eventually leading to an increased interfacial area between the phases, and augmented mass transfer. 


$$
\mathbf{L}=\mathbf{8 0} \mathbf{c m}
$$

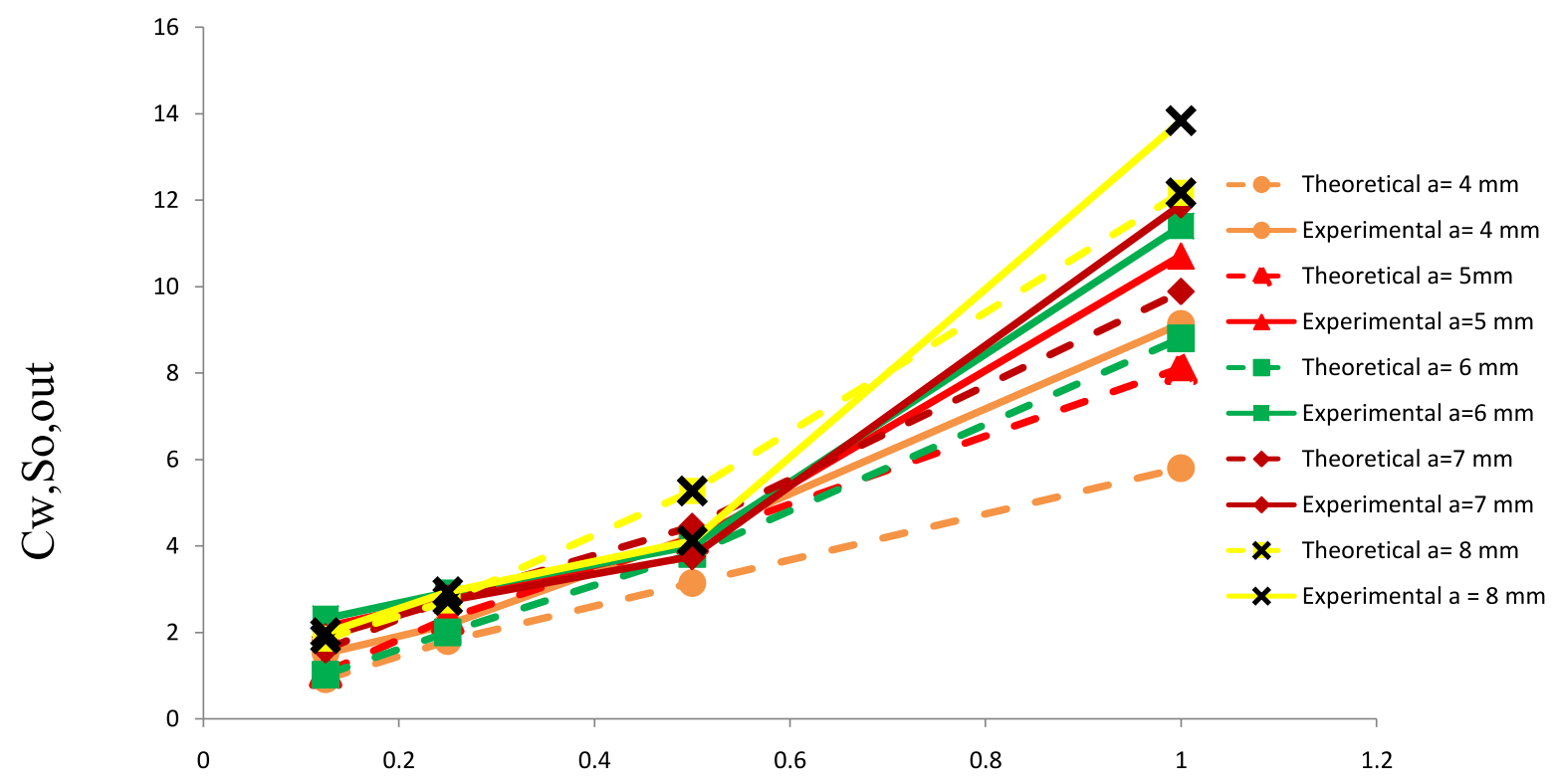

Frequency $(\mathrm{Hz})$

Figure 5: Theoretical validation of extracted concentration of salt in solvent extracted from saltwater with amplitude and frequency for $80 \mathrm{~cm}$ length of desalination unit having $19 \mathrm{~cm}$ of air damper attached at the top of the unit 


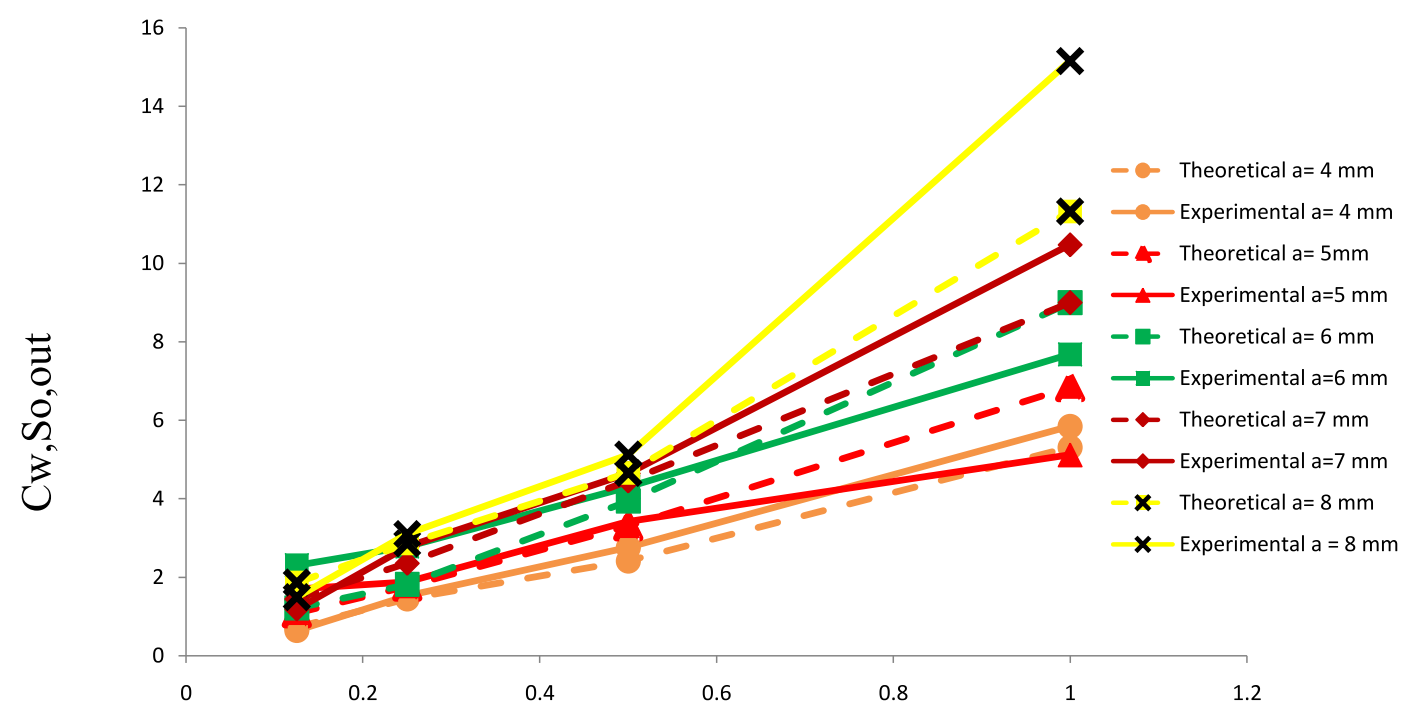

Frequency $(\mathrm{Hz})$

Figure 6: Theoretical validation of extracted water concentration in solvent from saltwater/sea water with amplitude and frequency for $142 \mathrm{~cm}$ length of desalination unit having $19 \mathrm{~cm}$ of air damper attached at the top of the unit

\section{Conclusion}

In this work, a theoretical desalination model for desaltation of salt water/ sea water with the help of solvent extraction is prepared. The speciality of the desaltation unit is that it is a milliscale ' $\mathrm{T}$ ' unit attached with an air-damper through which continuous pulsatile flow is maintained. The theoretical model is verified with the experimental results of the paper [37].

The work in this manuscript presents pulsatile liquid-liquid two phase mass transfer properties of a toluene-acetic acid-water system. The secondary pulsations created due to cushioning effect of air filled element combined with pulsations have been studied. The knowledge that mere increments of the length/ volume of the reactor for maximizing extraction do not lead to beneficial extraction process on a per unit power basis. It is established that the moderate and lesser length of the extraction column can also give higher extraction rate per unit power compared to the larger ones. Further, a detailed experimental analysis and optimization of the air damper are conceptualized in the upcoming work. 


\section{NOTATIONS}

$C_{W, \text { So,out }}=$ the final concentration of water which got extracted in the directional solvent

$C_{W, S o, i n}=$ the initial concentration of water in the directional solvent

$x=$ liquid level within the air damper

$\phi=$ phase difference between pulsations

$E=$ adiabatic constant of the gas

$\omega_{o}=$ angular frequency of the pulsation

$l=$ length of the desalination unit

$L_{o}=$ complete length of the air damper

$a=$ amplitude of the reciprocating pump, $\mathrm{mm}$

$A=$ cross sectional area, $m^{2}$

$\Delta t=$ change in time, secs

$f=$ frequency of toluene side dosing pump, $\mathrm{Hz}$

ID $=$ internal diameter

$k=$ mass transfer coefficient, $\mathrm{m} / \mathrm{s}$

$l=$ axial position in the central test section (made of $4 \mathrm{~mm}$ PU tube), $\mathrm{m}$

$m=$ slope of line between equilibrium concentration of water in solvent to concentration

of water in salt water

$k=$ linear stiffness of the gas

$E=$ adiabatic constant of the gas

$m_{l}=$ mass of the total liquid in the desalination unit

$\mathrm{OD}=$ outer diameter

$Q=$ volumetric flow rate of the phases, $\mathrm{m}^{3} / \mathrm{s}$

$r=$ internal radius of the $\mathrm{PU}$ tube in the central test section, $\mathrm{m}$

\section{GREEK LETTERS}

$\rho=$ density of the fluid, $\mathrm{kg} / \mathrm{m}^{3}$

$\omega=$ angular frequency of the flow pulsation, $\mathrm{rad} / \mathrm{s}$

$\tau=$ residence time of an imaginary fluid particle in the central limb of the desalination unit, secs

\section{SUBSCRIPTS}




$$
\begin{aligned}
& S o=\text { directional solvent } \\
& p=\text { piston } \\
& t=\text { tube } \\
& w=\text { water } \\
& \text { in }=\text { inlet } \\
& \text { out }=\text { outlet } \\
& S w=\text { salt water } \\
& S o=\text { solvent }
\end{aligned}
$$

\section{References}

[1] J. E. Miller, et al., Review of water resources and desalination technologies, Sandia National Laboratories, Albuquerque, NM 49 (2003) 2003-0800.

[2] A. Garciadiego, T. Luo, A. W. Dowling, Molecular design targets and optimization of low-temperature thermal desalination systems, Desalination 504 (2021) 114941.

[3] L. Yang, I. E. Grossmann, J. Manno, Optimization models for shale gas water management, AIChE Journal 60 (10) (2014) 3490-3501.

[4] S. Alotaibi, O. M. Ibrahim, S. Luo, T. Luo, Modeling of a continuous water desalination process using directional solvent extraction, Desalination 420 (2017) 114-124.

[5] J. Guo, Z. D. Tucker, Y. Wang, B. L. Ashfeld, T. Luo, Ionic liquid enables highly efficient low temperature desalination by directional solvent extraction, Nature Communications 12 (1) (2021) 1-7.

[6] G. D. Barbosa, J. E. Bara, S. T. Weinman, C. H. Turner, Molecular aspects of temperature swing solvent extraction for brine desalination using imidazole-based solvents, Chemical Engineering Science 247 (2022) 116866.

[7] R. Davidson, W. Smith Jr, D. W. Hood, Structure and amine-water solubility in desalination by solvent extraction., Journal of chemical and engineering data 5 (4) (1960) 420-423. 
[8] R. Davison, W. Harris, W. Smith Jr, A solvent extraction desalination pilot plant, Desalination 3 (1) (1967) 17-26.

[9] G. Johnson, Recovery of potable water from sea and brackish water by selective solvent extraction, uS Patent 3,823,000 (Jul. 9 1974).

[10] C. B. Ellis, et al., Fresh water from the ocean for cities, industry, and irrigation (1954).

[11] L. Lazare, The puraq seawater desalination process, Desalination 42 (1) (1982) 1116.

[12] L. Leon, Desalination of sea water, uS Patent 3,386,912 (Jun. 4 1968).

[13] R. R. Davison, D. W. Hood, Mixed solvents for saline water extraction, uS Patent 3,088,909 (May 7 1963).

[14] T. Luo, A. Bajpayee, G. Chen, Directional solvent for membrane-free water desalination - a molecular level study, Journal of Applied Physics 110 (5) (2011) 054905.

[15] H. A. Abdulbari, E. A. Basheer, Microfluidics chip for directional solvent extraction desalination of seawater, Scientific reports 9 (1) (2019) 1-11.

[16] D. B. Sanap, K. D. Kadam, M. Narayan, S. Kasthurirangan, P. R. Nemade, V. H. Dalvi, Analysis of saline water desalination by directed solvent extraction using octanoic acid, Desalination 357 (2015) 150-162.

[17] M. A. Darwish, Desalination engineering, Balaban Desalination Publication (2015).

[18] M. Isaka, Water desalination using renewable energy technology brief, IEA-ETSAP and IRENA(C) Technology Brief I12-March (2012).

[19] A. Al-Karaghouli, L. L. Kazmerski, Comparisons of technical and economic performance of the main desalination processes with and without renewable energy coupling, in: World Renewable Energy Forum, ASES, [Sl], 2012, pp. 13-17.

[20] K. E. Thomas, Overview of village scale, renewable energy powered desalination, Tech. rep., National Renewable Energy Lab., Golden, CO (United States) (1997). 
[21] A. Bajpayee, Directional solvent extraction desalination, Ph.D. thesis, Massachusetts Institute of Technology (2012).

[22] A. Bajpayee, T. Luo, A. Muto, G. Chen, Very low temperature membrane-free desalination by directional solvent extraction, Energy \& Environmental Science 4 (5) (2011) 1672-1675.

[23] O. K. Choi, J. H. Seo, G. S. Kim, Z. Hendren, G. D. Kim, D. Kim, J. W. Lee, Non-membrane solvent extraction desalination (sed) technology using solubilityswitchable amine, Journal of Hazardous Materials 403 (2021) 123636.

[24] W. Bank, The Role of Desalination in an Increasingly Water-Scarce World, World Bank, 2019.

[25] Y. Pei, Y. Zhang, J. Ma, M. Fan, S. Zhang, J. Wang, Ionic liquids for advanced materials, Materials Today Nano 17 (2022) 100159.

[26] M. Kaczmarczyk, B. Tomaszewska, W. Bujakowski, Innovative desalination of geothermal wastewater supported by electricity generated from low-enthalpy geothermal resources, Desalination 524 (2022) 115450.

[27] R. Chakraborty, P. Mukhopadhyay, M. Bera, S. Suman, Infrared-assisted freeze drying of tiger prawn: parameter optimization and quality assessment, Drying Technology 29 (5) (2011) 508-519.

[28] R. Chakraborty, H. Sahu, Intensification of biodiesel production from waste goat tallow using infrared radiation: process evaluation through response surface methodology and artificial neural network, Applied energy 114 (2014) 827-836.

[29] R. Chakraborty, D. RoyChowdhury, Fish bone derived natural hydroxyapatitesupported copper acid catalyst: Taguchi optimization of semibatch oleic acid esterification, Chemical engineering journal 215 (2013) 491-499.

[30] H. M. Hofmann, D. L. Movileanu, M. Kind, H. Martin, Influence of a pulsation on heat transfer and flow structure in submerged impinging jets, International Journal of Heat and Mass Transfer 50 (17-18) (2007) 3638-3648. 
[31] T. Nishimura, N. Kojima, Mass transfer enhancement in a symmetric sinusoidal wavy-walled channel for pulsatile flow, International Journal of Heat and Mass Transfer 38 (9) (1995) 1719-1731.

[32] B. Mehta, S. Khandekar, Taylor bubble-train flows and heat transfer in the context of pulsating heat pipes, International Journal of Heat and Mass Transfer 79 (2014) 279-290.

[33] A. Chakravorty, Process intensification by pulsation and vibration in miscible and immiscible two component systems, Chemical Engineering and Processing-Process Intensification 133 (2018) 90-105.

[34] R. S. Abiev, M. Vasilev, Pulsating flow type apparatus: Energy dissipation rate and droplets dispersion, Chemical Engineering Research and Design 108 (2016) 101-108.

[35] R. Chakraborty, A. Banerjee, Prediction of fuel properties of biodiesel produced by sequential esterification and transesterification of used frying soybean oil using statistical analysis, Waste and Biomass Valorization 1 (2) (2010) 201-208.

[36] D. Brogioli, F. La Mantia, N. Y. Yip, Thermodynamic analysis and energy efficiency of thermal desalination processes, Desalination 428 (2018) 29-39.

[37] A. Chakravorty, A. Maitra, A. Bandopadhyay, Liquid-liquid mass transfer enhancement due to t-junction modified with an air damper, Industrial \& Engineering Chemistry Research 58 (40) (2019) 18810-18821.

[38] S. H. Crandall, The role of damping in vibration theory, Journal of sound and vibration 11 (1) (1970) 3-IN1.

[39] S. M. Savaresi, C. Poussot-Vassal, C. Spelta, O. Sename, L. Dugard, Semi-active suspension control design for vehicles, Elsevier, 2010.

[40] A. Chakravorty, A. Maitra, A. Bandopadhyay, Optimization of semi-pulsatile liquidliquid extraction operations in milli-channels, The Canadian Journal of Chemical Engineering (2021). 